\title{
Evaluation of a client held record introduced by a community mental health team
}

\author{
Anna Stafford and Richard Laugharne
}

\begin{abstract}
A client held record for patients with long-term mental Illness was introduced by a community mental health feam in east London. The record was evaluated by asking the opinions of 45 patients and examining how their cllent record had been used. Over $80 \%$ of the patients found the record and the information it contained useful, $74 \%$ of contacts were recorded in the booklet and the cllent held record had begun to be used by many professionals for purposes other than appointments and medication. A client held record can increase patient involvement in care and help communication between professionals.
\end{abstract}

The Health of the Nation strategy includes the principle that users of mental health services "should be involved as far as possible in the care process" (Department of Health, 1995). Access to records and client held records are ways of increasing that involvement (Laugharne \& Stafford, 1996). In a survey of psychiatric outpatients' views on different types of health record carried out by McLaren et al (1993) most people expressed a preference for a record they could keep and read. The client held record piloted by Essex (1990) indicated that it could increase client satisfaction and help communication. We report the introduction and evaluation of a client held record with a community mental health team in east London covering a deprived innercity area of the London Borough of Tower Hamlets.

The client held record was introduced in order to give people more information about their care and treatment and to improve communication between health professionals. It was developed in consultation with users and providers of mental health services. The resulting booklet was pocket-sized to make it easy to carry and divided into sections so that the information it contained was clear. The three main sections were appointments, notes and medication. In addition there was a crisis page, a care plan. pages for early warning signs and telephone numbers of the key people involved in the person's care. The record was aimed at people with long-term mental health problems. although people with short-term problems were not completely excluded if it was felt it could be useful for them. It did not affect the record keeping systems that clinicians already had in place and it was up to the patient whether or not they wished to hold the record.

\section{The study}

The sample selected consisted of patients who had been issued with a record by the community mental health team by 1 November 1995. People who had been offered and refused a record were not included.

The first part of the evaluation was a survey of the holder's views of the record. This comprised a short semi-structured interview consisting of seven questions similar to those used by Essex et al (1990). Record holders were asked if they found the record useful, whether the information it contained was useful and if there was other information they thought should be included. They were asked about aspects of the record they liked or disliked and if it could be improved in any way. In addition they were asked if they liked to see what was written about them.

The project worker also examined their records in order to see how they were used. A form was completed which noted the dates of entries, who they saw and which section they were in. The interviews themselves were carried out by the project worker in the setting in which the person was normally seen, most frequently a depot clinic or their home. Three people were in-patients and were interviewed on the ward, the remaining two were interviewed in other settings, a general practitioner's surgery and a community centre. In one instance the project worker was accompanied by a health care assistant who acted as a translator for a Bengali speaking person and on a few occasions another member of the interviewee's family was present, in one case helping to answer questions for an interviewee with speech problems. 


\section{Findings}

There were 56 patients included in the study, all of whom had long-term mental health needs, the most common primary diagnosis being schizophrenia (40) followed by affective psychosis (10), neurosis (3) and three patients had other diagnoses. The age range was 23-63 with a mean of 46 (31 women and 25 men).

Forty-five people out of the total sample were interviewed. Of the remainder (11) four refused to take part in the survey, one agreed but the interview was cancelled the day before because of a distressing incident and five were not asked, either because their keyworker felt it inappropriate (2) or forgot (3) and one person was in hospital undergoing major surgery. The length of time the record had been used ranged from two to 14 months with a mean of just over six months. Of those interviewed nine people did not have their record with them. One person did not use it for visits but kept it at home for the telephone numbers, one forgot to bring it with them and seven no longer used the booklet at all having lost, or given it away.

Eighty-four per cent of the patients found the record useful and $80 \%$ found the information it contained useful (Table 1). The information most often cited as being useful was appointments (25), followed by telephone numbers (13), information about medication (6), notes (2) and early warning signs (1). Twenty-seven people felt they did, or would like to see, what was written about them and eight would not like to.

The majority (36) suggested at least one aspect that they liked, five did not know or did not reply and four replied 'none'. Nine people said that it was handy or convenient, for example 'Size is handy, handy to have all the information in one place, fits in pocket'. Other aspects that were appreciated included helping communication between professionals, that the professionals knew what was going on, having information about medication, ease of use, helping to relate to keyworker and use as an identity card.

Seven people suggested aspects that they disliked. Four people commented on its size, three suggesting it should be larger and one smaller, two people said they did not like writing in it, one person felt it was a tangible piece of

Table 1. Views of patients issued with a client held record, $n=45$

\begin{tabular}{lll}
\hline Response & Care booklet usetul & Information usetul \\
\hline Yes & 38 & 36 \\
No & 6 & 5 \\
Don't know & 1 & 4 \\
Total & 45 & 45 \\
\hline
\end{tabular}

evidence of their illness, and one person said that the doctor did not take any notice of it.

Suggestions for improvements or additional information included more information about the effects of medication, how to get an emergency doctor, adding a diary section, putting in writing that there is no pressure to use the record and having information about how you are feeling so that you can talk to the doctor.

It was possible to compare entries in the client held record with entries in the mental health team's own notes for 35 patients. A total of 605 (mean 17.28) face-to-face contacts were made in the team notes, compared to 449 (mean 12.82) in the care booklets. Thus $74 \%$ of all team contacts were recorded in the care booklet.

In all cases the personal details, professionals and agencies involved pages and the appointment sections were used, in all but three cases entries had been made in the medication section. Over $50 \%$ had at least one entry in the notes section and the crisis page had been completed in nearly $50 \%$ of the records seen. The least useful sections were the blank pages and the early warning signs. Slightly more had care plans (Table 2).

A range of people were represented in the appointments pages. The care plans were almost always written by a community mental health nurse although there were two exceptions to this. a joint care plan completed both by a community mental health nurse and a social worker and another that was completed by the user, signed by an occupational therapist. The early warning signs pages had all been written by a nurse. A wider range of people, however, had made an entry in the notes in at least one record. These included community mental health nurses, psychiatrists, a health care assistant, patients. general practitioners, social workers, voluntary sector workers, a practice nurse, a hospital nurse, a medical consultant and a carer.

Table 2. Sections used in the client held record. $n=38$

\begin{tabular}{lc}
\hline Section & $\begin{array}{l}\text { Care booklets } \\
n(\%)\end{array}$ \\
\hline Professionals and agencies involved $38(100)$ \\
Appointments & $38(100)$ \\
Medication & $35(92)$ \\
Notes pages & $20(53)$ \\
In an emergency (crisis page) & $18(48)$ \\
Care plan & $9(24)$ \\
Early warning signs & $7(18)$ \\
Blank pages & $7(18)$ \\
\hline
\end{tabular}




\section{Comments}

The response of users of the record was positive with at least $80 \%$ finding the record useful, the information it contained useful and aspects of the record which they liked. This replicates the findings of Essex et al (1990) that a client held record is acceptable to patients. Aspects that were particularly appreciated were convenience of use and having information in one place. People also appreciated having information about their medication, which generally consisted of the name and dose of the drug. Some people said they would like more information about medication and its effects. It is interesting to note that only one person who was actively using their care booklet forgot to bring it with them at the time of the interview indicating that people generally remember to bring it.

Significantly of the 35 booklets examined and compared to the community mental health team notes, $74 \%$ of contacts had been recorded in the client held record. This compares to the Essex (1990) finding of $65 \%$ of patients taking their record to more than $75 \%$ of follow-up visits, $20 \%$ to between 50 and $75 \%$ of visits and $14 \%$ to less than $50 \%$ of visits. This study did not examine the client held record.

That all the sections were beginning to be used indicated that the patients were involved in the process. The early warning signs page requires active involvement by the patient and these had been used on seven occasions. The fact that most people said they would like to see what was written about them indicates that many users would like more involvement. Two of the people who did not find the record useful said that they would be interested to see what was written about them, implying that if the booklet did contain more information they might find it useful.

The wide range of people who had made entries in the notes section indicated the willingness of some professionals to use the record. Although there are a few examples of a record being used as a tool for a communication between professionals as well as helping communication between user and professional there is also room for development in this area. It should also be noted that one person commented that the doctor did not take any notice of their record indicating that some professionals might be reluctant to use the record.

In conclusion, we have introduced a client held record for a group of patients with long-term mental health needs. The use of the record has slowly become established and most patients who used it found it acceptable and useful. A wide range of professionals have begun to write in it. This new development has potential to improve communication between professionals and between patient and professional, as well as fulfilling the requirement to increase patient involvement in care.

\section{References}

DEPARTMENT OF HEALTH (1995) Building Bridges. London HMSO.

Essex. B., Dolg. R. \& REnSHaw, J. (1990) Pilot study of records of shared care for people with mental illness. Brttish Medical Journal, s00. 1442-1446.

LAUGHARNE, R. \& STAFFORD, A. (1996) Access to records and client held records: a review of the literature. Psychiatric Bulletin, 20, 338-341.

MClaren, P. M., WATSON, R., WOOster, A., et al (1993) Assessing medical records: Patient preferences and knowledge. Journal of Mental Health. 2. 175-181.

*Anna Stafford, Care Programme Approach Coordinator, Tower Hamlets Healthcare Trust. and Richard Laugharne, Senior Registrar, St George's Medical School, London

*Correspondence: The Royal London Hospital (St Clement's), 2A Bow Road, London E3 4LL 